\title{
Impact of surgery on quality of life in Crohn's disease: short- and mid-term follow-up
}

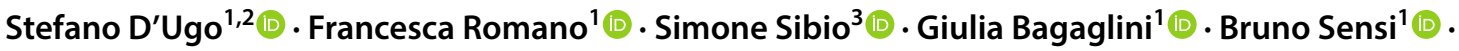

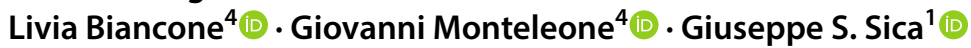

Received: 19 June 2019 / Accepted: 4 March 2020 / Published online: 17 March 2020

(C) Italian Society of Surgery (SIC) 2020

\begin{abstract}
Active Crohn's disease has a substantial impact on Quality of Life (QoL). Medical management could be associated to side effects, hospitalization, long treatment period and requires patient's compliance, impacting QoL. Ileocecal resection (ICR) is often required, open or laparoscopic. Aim of the study was to assess Health-Related (HR) QoL changes following ICR, and to identify factors impacting on QoL in the short and mid-term. From a single institution, we created a prospective database of patients undergoing ICR from 01/2009 to 12/2015. HRQoL was analysed with Cleveland Global Quality of Life (CGQL) score, Overall Quality of Happiness $(\mathrm{OQH})$, and asking patients if they would have surgery again. QoL scores were recorded at 30 days, 6, 12 and 36 months postoperatively and compared according to follow-up timing, technique, medical treatment and demographics. Statistical analysis included 187 patients. Mean follow-up was $3.8 \pm 2.9$ years. Both at 30 days and 6 months postoperatively, CGQL, its items and OQH increased significantly $(p<0.001)$. Increased values were also recorded at 1 and 3 years; $88 \%$ of patients would undergo surgery again. Laparoscopy was associated with improved CGQL scores, while preoperative steroids with worsen data. Young female patients, with penetrating pattern, experienced greater HRQoL improvements. Surgery is associated with improvements of HRQoL and patients' happiness in the short and mid-term. Laparoscopy, steroid-free and young patients showed the best results. ICR should be considered a reasonable alternative to non-operative strategies in selected cases.
\end{abstract}

Keywords Crohn's disease · Surgery · Quality of life · Laparoscopy $\cdot$ Laparoscopic surgery

\section{Introduction}

Crohn's disease (CD) is an incurable inflammatory bowel disease (IBD) characterised by a chronic, relapsing course. The incidence is increasing worldwide, although CD is still most common in Europe and North America [1-3]. To obtain an acceptable control of symptoms, CD is usually managed by gastroenterologists and surgeons together.

Stefano D'Ugo

dugo.stefano@gmail.com

1 Gastrointestinal Surgery Unit, Tor Vergata University Hospital, Viale Oxford 81, 00133 Rome, Italy

2 Present Address: Department of Surgery, "Vito Fazzi" Hospital, Piazza F. Muratore, 73100 Lecce, Italy

3 Department of Surgery, La Sapienza University, P.le A. Moro, Rome, Italy

4 Gastroenterology Unit, Tor Vergata University Hospital, Viale Oxford 81, 00133 Rome, Italy
Although the treatment of choice is sometimes more or less clear-cut, in many cases, both medical and surgical treatments could be justified [4].

The relatively young age of onset of $\mathrm{CD}$, its associated morbidity, debilitating symptoms, and occasionally disfiguring complications could potentially cause significant psychological stress, influencing multiple aspects of everyday life $[2,5]$.

Large studies showed that symptoms of active CD such as diarrhoea, abdominal pain, gastrointestinal bleeding have a substantial impact on Health-Related Quality of Life (HRQoL) [6-8]. Even in the absence of active disease, CD patients report worse HRQoL than those without [9, 10]. On the other hand, achievement of disease remission, whether by medical therapies or surgery, is associated with an improvement of Quality of Life (QoL) [11, 12].

Quality of life is a multidimensional concept, which includes multiple factors like patient's perception, functional status and social perspectives. Several studies have 
also shown that QoL and psychological issues have a great impact on the course of IBDs [13, 14]. Drossman et al. reported how functional status and patient concerns correlate better with health status and previous health care utilization than the physician's rating of disease activity [10].

Medical management is the mainstay for CD; however, it could be associated to side effects of multiple drugs, need of hospitalization for infusion, long treatment periods and requires a constant patient's compliance. Those aspects can have an impact on QoL, patient's perspective and social life [15].

Over the years, more and more medications for CD, including biologics, have been developed, with benefits for many patients. However, despite this, many of them require surgery at some point of their lives. HRQoL of those patients is usually poor, but improves following the resectional treatment. Ileocecal resection (ICR) has been seen associated with some short-term improvement of QoL, although data are controversial and not clearly confirmed in the longer term follow-up [16-19].

The aim of this prospective study was to assess changes of QoL following ileocecal resection for $\mathrm{CD}$, both open and laparoscopic. We tried to identify specific factors, patient and disease-related, associated with improved QoL after surgery in the short and mid-term. Although patients were not randomised between medical and surgical treatment, the large sample size and the detailed analysis of HRQoL gave considerable results.

\section{Methods}

From January 2009 to December 2015, all the patients with diagnosis of CD undergoing ICR in our surgical unit were prospectively entered into a database. Diagnosis of CD and indication for surgery were made according to guidelines and conventional criteria, in agreement with the gastroenterologists. Patients' demographics, habits (i.e., smoking) and comorbidities were recorded. Data included duration of CD and disease features.

Patients were sub-classified according to the Montreal classification: B1-non-stricturing, non-penetrating; B2-stricturing; B3-penetrating; P-perianal disease. Extra-intestinal manifestations and previous procedures for $\mathrm{CD}$ were also analysed. Records of medical therapies before surgery with either steroids (budesonide, prednisone, methylprednisone) or biologics (infliximab, adalimumab, certolizumab) were prospectively collected.

According to the surgical approach, patients were classified into two groups: laparoscopic or open ICR. Postoperative data included length of stay (LOS) and complications according to Clavien-Dindo classification. For LOS assessment, it is to mention that an Enhanced Recovery (ERAS) protocol was applied only during the last 18 months of the study. Cases with other procedures besides ICR were excluded from the analysis.

Assessment of HRQoL by means of a specific questionnaire was done at 30 days, 6 months, 12 months and 3 years after surgery.

Postoperatively, all patients were treated with mesalazine $2.4 \mathrm{~g}$ per day as a prophylaxis for recurrence. Assessment of clinical recurrence was performed at each postoperative medical evaluation, and the treatment was modified accordingly (steroids and/or step-up to thiopurines or anti-TNF).

\section{Health-related quality of life}

Quality of life was analysed through the Cleveland Global Quality of Life (CGQL) score, with a range from zero (worse) to one (best). The final score was achieved recording three items: Current Quality of Life (CQoL), Current Quality of Health (CQoH), Current Energy Level (CEL). Each item was recorded with a score ranging from 0 (worse) to 10 (best); the sum of the 3 scores divided by 30 gave the final CGQL score.

The CGQL questionnaire and its items were first submitted to the patients at the time of enrolment in the study, before surgery. Afterwards, at every follow-up appointment, patients filled in a new CGQL questionnaire, based on their present condition.

In addition, an independent item, the Overall Quality of Happiness $(\mathrm{OQH})$ with the medical condition was recorded at each observation time (score from zero to ten). We also asked patients whether they would have surgery again in a similar condition of illness and/or they recommend the same treatment to others.

CGQL score, including all the items, and $\mathrm{OQH}$ were compared according to the timing of record, and the same was done for preoperative and postoperative data. Assessment of the results was also done dividing the patients in two main groups, based on the surgical technique, open or laparoscopy.

Patients were split into further subgroups, according to the medical treatment before surgery. CGQL scores for patients who undergone therapy with steroids or biologics for more than 1 year were compared to those with no longterm drugs, with pre- and post-surgery comparisons.

An evaluation of a possible impact of patients' demographics and disease features was performed comparing postoperative CGQL results between males and females, more or less than 40 years of age, previous procedures for $\mathrm{CD}$ and pattern of $\mathrm{CD}$ behaviour.

Statistical analysis was performed using the Student's $t$ test for continuous variables and the Chi-square test for categorical variables. Results are expressed as mean values ( \pm Standard Deviation) if not stated otherwise. All tests were 
double sided and the level of statistical significance was set at a $p$ value of less than 0.05 .

\section{Results}

During the study period, 187 consecutive patients undergoing elective ICR for CD were considered for statistical analysis. Patients' demographics and preoperative data are summarized in Table 1.

There were no significant preoperative differences in the groups undergoing steroids or biologics therapy, apart from the need of those medications due to the disease status.

Overall, $101(54 \%)$ patients were operated with a laparoscopic approach, while the remaining 86 (46\%) underwent open procedures. However, in the second half of the study period, laparoscopy was the standard approach, with about $80 \%$ of cases done with this technique.

The mean operative time was $92 \pm 48 \mathrm{~min}$, and the mean LOS was $8.5 \pm 5.3$ days. After surgery, $31(16 \%)$ patients

Table 1 Patients' demographics and preoperative data

\begin{tabular}{|c|c|}
\hline & $N=187(\%)$ \\
\hline \multicolumn{2}{|l|}{ Gender } \\
\hline Male & $112(60)$ \\
\hline Female & $75(40)$ \\
\hline \multicolumn{2}{|c|}{ Age at diagnosis } \\
\hline$<40$ years & $86(46)$ \\
\hline$>40$ years & $101(54)$ \\
\hline Mean BMI & 22 \\
\hline \multicolumn{2}{|l|}{ Smoking } \\
\hline Yes & $87(46)$ \\
\hline No & $100(54)$ \\
\hline \multicolumn{2}{|l|}{$\mathrm{CD}$ duration } \\
\hline$<10$ years & $99(53)$ \\
\hline$>10$ years & $88(47)$ \\
\hline \multicolumn{2}{|c|}{ Montreal classification } \\
\hline B2 & $114(61)$ \\
\hline B3 & $73(39)$ \\
\hline \multicolumn{2}{|c|}{ Extra-intestinal disease } \\
\hline Yes & $41(22)$ \\
\hline No & $146(78)$ \\
\hline \multicolumn{2}{|c|}{ Previous procedures } \\
\hline Yes & $44(23)$ \\
\hline No & $143(77)$ \\
\hline \multicolumn{2}{|c|}{ Preoperative steroids } \\
\hline Yes & $132(70)$ \\
\hline No & $55(30)$ \\
\hline \multicolumn{2}{|c|}{ Preoperative biologics } \\
\hline Yes & $69(37)$ \\
\hline No & $118(63)$ \\
\hline
\end{tabular}

experienced one of the complications, classified according to the Dindo-Clavien classification (Table 2). The vast majority of them had a minor deviation from the normal postoperative course. Among the five $(2.7 \%)$ patients in the grade III, three $(1.6 \%)$ had anastomotic leak. Two of them underwent reoperation with ileostomy; one was managed conservatively with bowel rest and antibiotics. The remaining two complications were one intra-abdominal collection, managed with percutaneous drain, and one endoluminal bleeding from the staple line, managed endoscopically.

Two $(1.1 \%)$ patients had an "elective" stoma during the indexed ICR, because of the estimated high risk of anastomotic leak.

Mean follow-up was $3.8 \pm 2.9$ years. At 30 days, $100 \%$ of the patients had a follow-up evaluation; after 6 months, they were $96 \%$ of the total, decreasing at $90 \%$ and $82 \%$ at 1 year and 3 years, respectively.

Clinical recurrence was observed in $5(2.7 \%)$ patients at 1 year, and in $12(6.4 \%)$ patients at 3 years follow-up. Clinical remission was induced by budesonide or prednisone, followed by anti-TNF or thiopurines.

\section{Quality of life scores}

Among the entire study group, 140 patients (75\%) completed the CGQL questionnaire, administered at each staged time during the follow-up.

At both 30 days and 6 months after surgery, we observed a significant increase of CGQL $(p<0.001)$. Incremental values were also recorder at 1 year, although with a minor increase, reaching a sort of plateau at 3 years after ICR (Fig. 1).

A significant improvement was observed in all the three items composing the CGQL taken individually and recorded during the same follow-up ( $p<0.001)$ (Fig. 2). This trend was also confirmed from the Overall Quality of Happiness Score (Fig. 3).

Moreover, the incremental value of the previous scores about QoL, compared to the preoperative situation, was constant up to 1 year of follow-up; after that, we observed a steady state, but no regression up to 3 years from surgery (Fig. 4).

At the question if patients were pleased enough with the indexed operation and if they would undergo surgery again,

Table 2 Postoperative complications according to Dindo-Clavien grading

\begin{tabular}{ll}
\hline Grade & $N(\%)$ \\
\hline I & $17(9)$ \\
II & $9(4.8)$ \\
III & $5(2.7)$ \\
IV & - \\
V & - \\
\hline
\end{tabular}




\section{CGQL}

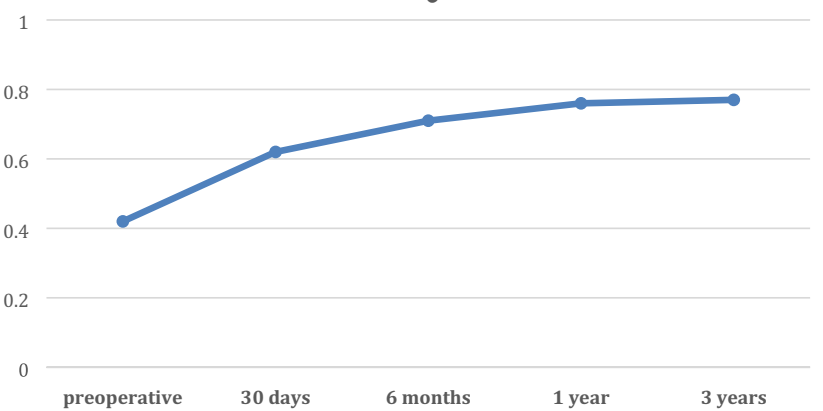

Fig. 1 Cleveland Global Quality of Life (CGQL) score after surgery

\section{CGQL items}

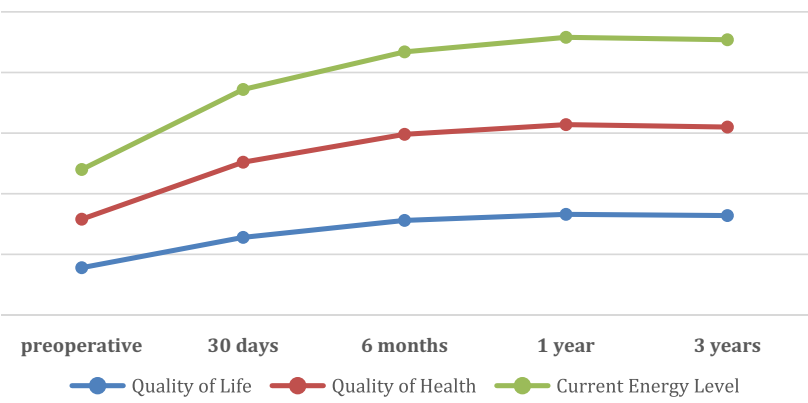

Fig. 2 Improvement of the CGQL items postoperatively

\section{Quality of happiness}

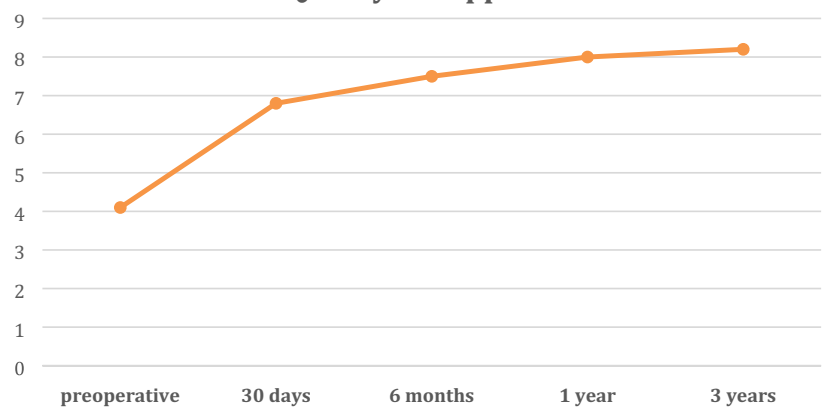

Fig. 3 Trend of Overall Quality of Happiness (OQH) after ICR

or recommend it to others, the vast majority of them (88\%) answered with positive results.

Comparison of CGQL scores between the two surgical techniques, open and laparoscopy, showed a stronger association with the minimally invasive technique. This was significant up to 6 months after surgery, although even after that, the trend was the same (Fig. 5).

As for the previous evaluation, similar results were observed also for the other QoL and OQH scores, with improved incremental values after laparoscopy.
CGQL items: incremental values

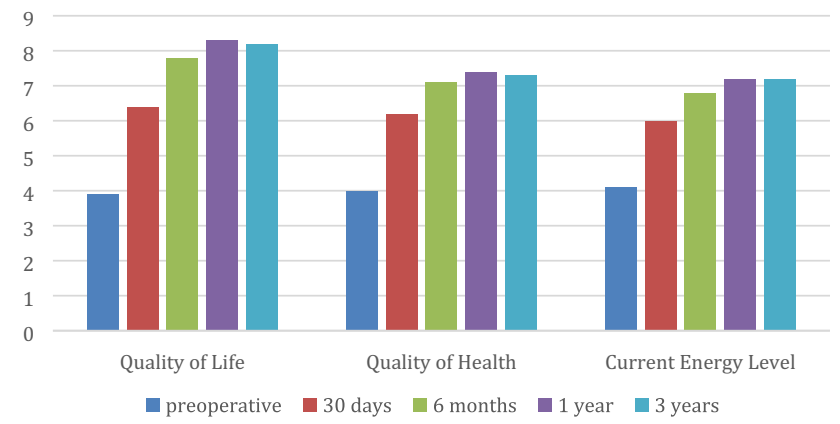

Fig. 4 Increment of each value composing the CGQL after ICR

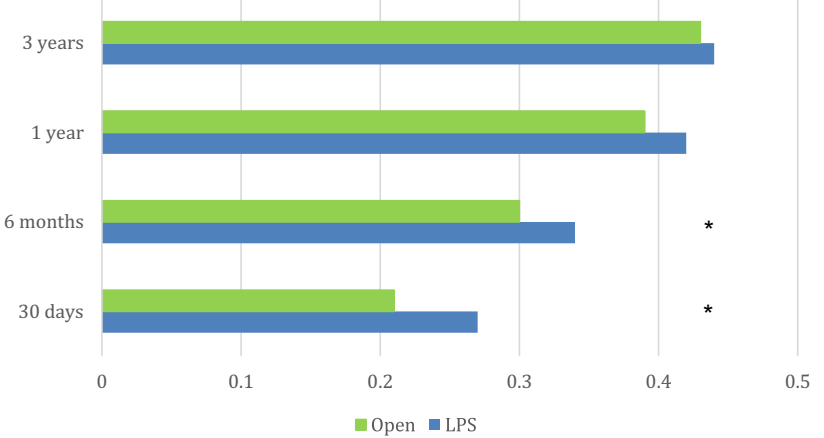

Fig. 5 Postoperative CGQL values according to the surgical technique. $* p<0.05$

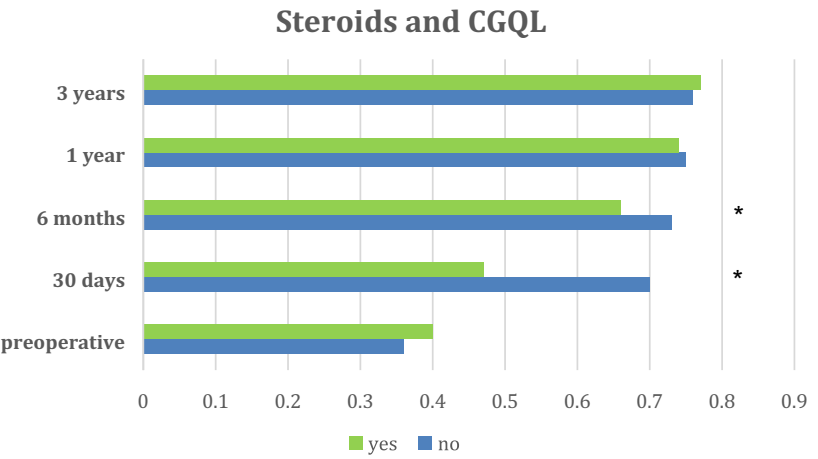

Fig. 6 Effects of preoperative steroids on CGQL scores after surgery. $* p<0.05$

Patients treated for long term ( $>1$ year) with steroids for bowel disease before surgery showed a significant minor improvement in CGQL, at 30 days and 6 months, compared to those treated with steroid-free or post-short-course treatment $(<1$ year) (Fig. 6).

A similar picture was recorded with biologic drugs before surgery, but with no statistical significance.

The multivariate analysis of relationship between demographics, preoperative data and postoperative QoL scores 
showed better results for patients younger than 40, female, with penetrating pattern of $\mathrm{CD}$ (B3), with no history of previous procedures (Table 3 ).

\section{Discussion}

After the diagnosis of Crohn's disease, quality of life of patients reduces, and it could be quite poor [6-10]. At present, in the vast majority of cases, the first-line treatment for $\mathrm{CD}$ is one of the medical therapies available. Despite the reasonable good results, drugs themselves may impact the QoL because of side effects, hospitalization, and need of long period of therapy [15].

At some point of their lives, about $70-80 \%$ of CD subjects will require bowel surgery, and up to $70 \%$ of these patients will need a second operation because of recurrent disease [20]. Postoperative recurrence is deeply investigated to prevent the need for further surgery [21-25].

HRQoL of patients referred for surgery is poor, because of possible several factors: disease that is more complicated, impaired nutritional status, long hospital admission for nonresponding medical treatment, abscesses or other concurrent problems [16]. A few studies in the available literature showed that ICR is able to improve HRQoL of CD patients in the short term [16-18]. However, it is not clear if these results are durable in the longer term follow-up, when other factors like recurrent disease, may affect QoL itself [19, 26, 27].

Already in 1999, Tillinger et al., in a small study on 16 patients, observed better QoL scores after surgery for CD [18]. Following this, Delaney et al. in a prospective study investigated the effects of surgery in CD patients on QoL, using the Cleveland Global Quality of Life (CGQL) scores submitted to 82 of them. In the early postoperative period (30 days), they observed a significant improvement of QoL, in particular in female and in those with no complications [17].

On the other hand, a large study on 3852 patients with diagnosis of CD showed a reduced QoL score in those previously submitted to bowel resection [28]. The result may be associated to the increased disease severity, and then a lower QoL, in the surgical group. However, this could be also a consequence of surgery in the longer term, with factors like smoking, personality and body image all being observed to affect QoL following an operation [18, 19, 29-31].

In our study, the evaluation of changes in QoL after surgery has been done using a detailed score. Being the final score made by several data, the CGQL gives a wide assessment of factors influencing QoL after surgery. In the shortterm follow-up, operative treatment is associated to a clear improvement of the patients' condition; the curve of incremental values is increasing constantly up to 12 months, with a steeper shape in the early phase. Those changes, compared to preoperative scores, are highly significant, and in line with other reported literature data [16-18].

In the mid-term follow-up, from 1 to 3 years, the degree of CGQL improvement is reduced but still visible. The possible explanation is that at this stage, surgery is far away, and its main benefits are already consolidated. However, we think is remarkable the absence of a reverse trend in the values; in fact, at this stage, factors like adhesions, chronic pain from the wound, or even recurrent disease could potentially play a role in the QoL. According to the study results, if they have a real impact on the patients, this is not enough to reduce their QoL.

Positive results and significant improvements have been seen in all the measured items of the CGQL. These data, associated to the significant increased $\mathrm{OQH}$, showed how the surgical treatment seems to have a positive impact in all the aspects of patients' everyday lives. The great majority of patients recommended the same surgery to others; this might
Table 3 CGQL according to specific factors

\begin{tabular}{lllllll}
\hline & Preop & 30 days & 6 months & 1 year & 3 years & $p^{*}$ \\
\hline Gender & & & & & & 0.056 \\
$\quad$ Male & 0.41 & 0.56 & 0.61 & 0.65 & 0.70 & \\
$\quad$ Female & 0.37 & 0.61 & 0.70 & 0.75 & 0.80 & \\
Age (years) & & & & & & 0.053 \\
$\quad<40$ & 0.38 & 0.57 & 0.64 & 0.70 & 0.78 & \\
$>40$ & 0.36 & 0.51 & 0.59 & 0.65 & 0.72 & \\
Disease pattern & & & & & & 0.059 \\
B2 & 0.38 & 0.58 & 0.66 & 0.70 & 0.73 & \\
B3 & 0.40 & 0.63 & 0.71 & 0.76 & 0.81 & \\
Previous procedures & & & & & & 0.055 \\
$\quad$ Yes & 0.36 & 0.48 & 0.60 & 0.67 & 0.72 & \\
No & 0.45 & 0.59 & 0.68 & 0.75 & 0.79 & \\
\hline
\end{tabular}

*Multivariate analysis 
reflect a role of the operative treatment in the reduction of psychological stress and the improvement in the social life.

Benefits of laparoscopic surgery over the open approach are well established; from reduced pain, scar and inflammatory response to quicker recovery and shorter length of stay, benefits for patients are multiple [32-36]. These aspects probably explain also the improved QoL after the minimally invasive ICR compared to laparotomy [37]. In detail, the benefit is mainly seen early after surgery, because of the above-mentioned advantages of laparoscopy, and in young patients, more motivated to go back to a normal social life.

In the vast majority of cases, after diagnosis of $\mathrm{CD}$, patients are assigned to one of the medical treatments available. When symptoms are not controlled, gastroenterologists may decide to go for long period of steroids, or to switch to biologic drugs [38]. Eventually, some of these patients are not responder to medications, and they are sent for surgery [39-43]. Long treatment period, possibility of side effects of drugs, malnutrition and complicated disease are all risk factors for worse results after surgery [15, 44-46]. From the results of our study, there is evidence that prolonged steroid use before surgery is associated to a significant reduced improvement of CGQL after ICR; the same trend was observed with biologics, although without statistical significance. Instead, an analysis of patients' outcomes according to the different postoperative treatments (steroids or immunosuppressants) was not possible, due to the low number of recurrences.

Theses data support the idea that the traditional treatment pathway needs to be reconsidered. The concept of surgical resection only after failure of all the medical therapies could potentially put the patient at higher risk of complications and be associated to worse QoL both in the short and mid-term. Scattered studies in the available literature raised the question if surgery could be a primary treatment for ileocecal $\mathrm{CD}$, instead of medications.

Gerdin et al., under the Swedish Crohn Trial, designed a randomised control trial to compare thiopurines vs open surgery in this setting. Although the study ended up being underpowered for the primary endpoint, represented by the CDAI index over time, it showed interesting results about the subjective health status of the patients. They randomised 36 patients to be allocated to medical or surgical treatment. The first group was managed with budesonide to induce remission and azathioprine for maintenance; the second group with ileal or ileocecal resection of macroscopically inflamed bowel with free resection margins. At follow-up of 1 year, the self-estimated health, measured with the SF36, was significantly higher for the surgical patients. In the long-term follow-up, the difference became not significant, but surgery appeared to be at least as equal as the medical therapy [47].

The very recent LIR!C Trial, randomised controlled, open-label, multicentre study enrolled patients with ileocecal
CD non-responder to conventional therapy, comparing laparoscopic surgery vs infliximab. The primary outcome was quality of life on the Inflammatory Bowel Disease Questionnaire (IBDQ) at 12 months, and the SF36 was among the secondary outcomes. Results from the 73 patients of the resectional group and the 70 patients treated with biologics were similar; and no major differences were seen in complications and side effects. The authors concluded asserting that ICR, in cases with limited disease, could be considered a reasonable alternative to infliximab, after failure of conventional therapy [48].

Our study, although had a different enrolment of patients, and was not primarily dedicated to compare medicine vs surgery, showed results that are in line with the above-mentioned findings. Ileocecal resection, mainly with minimally invasive technique, is able to improve the HRQoL of CD patients at different levels of activity and both in the short and mid-term.

We acknowledge some bias; it is not a prospective study, but data were prospectively entered for every patient over the years. Data were not collected from multiple centres; however, our institution is a tertiary centre with international guidelines. Patients were treated according to the standard pathway of medical therapy first, and not randomised between medication and surgery, which was considered unethical and not evidence-based at the time of patients' allocation. Nevertheless, the number of patients included, and the detailed analysis dividing them into subgroups, allow making some interesting consideration about QoL.

In conclusion, patients with diagnosis of Crohn's disease undergoing ileocecal resection have improvement of HRQoL and happiness after surgery. The operative treatment obtains significant results mainly in the short term, but they remain durable in the mid-term.

Laparoscopy, absence of preoperative steroids and younger patients are associated with better results.

Surgery should not only be seen as the last resort after failure of all medical therapies, but as a reasonable alternative to non-operative strategies in selected cases with limited disease. Further studies with long-term follow-up are required to clarify the exact role of surgery.

Author contributions All authors helped to perform the research. Conception and design of the study: SD, GSS, LB, GM. Acquisition, analysis and interpretation of data: SD, FR, SS, GB, BS. Drafting and revision of the article: SD, GSS. Final approval: GSS, GM, SD.

Funding None.

\section{Compliance with ethical standards}

Conflict of interest The authors declare that they have no conflict of interest. 
Research involving human participants and/or animals All procedures performed in this study were in accordance with the ethical standards of the institutional research committee and with the 1964 Helsinki declaration and its later amendments or comparable ethical standards.

Informed consent Informed consent was obtained from all individual participants included in this study.

\section{References}

1. Hovde $\varnothing$, Moum BA (2012) Epidemiology and clinical course of Crohn's disease: results from observational studies. World J Gastroenterol 18(15):1723-1731

2. Peyrin-Biroulet L, Cieza A, Sandborn WJ, Kostanjsek N, Kamm MA, Hibi T, Lémann M, Stucki G, Colombel JF (2010) Disability in inflammatory bowel diseases: developing ICF Core Sets for patients with inflammatory bowel diseases based on the International Classification of Functioning, Disability, and Health. Inflamm Bowel Dis 16(1):15-22

3. Peyrin-Biroulet L, Loftus EV Jr, Colombel JF, Sandborn WJ (2011) Long-term complications, extraintestinal manifestations, and mortality in adult Crohn's disease in population-based cohorts. Inflamm Bowel Dis 17(1):471-478

4. Andersson P, Olaison G, Bodemar G, Almer S, Arvidsson M, Dabrosin-Söderholm J, Nyström PO, Smedh K, Ström M, Sjödahl R (1998) Low symptomatic load in Crohn's disease with surgery and medicine as complementary treatments. Scand J Gastroenterol 33(4):423-429

5. Peyrin-Biroulet L, Cieza A, Sandborn WJ, Coenen M, Chowers Y, Hibi T, Kostanjsek N, Stucki G, Colombel JF (2012) Development of the first disability index for inflammatory bowel disease based on the international classification of functioning, disability and health. Gut 61(2):241-247

6. Ghosh S, Mitchell R (2007) Impact of inflammatory bowel disease on quality of life: results of the European Federation of Crohn's and Ulcerative Colitis Associations (EFCCA) patient survey. J Crohns Colitis. 1(1):10-20

7. Schirbel A, Reichert A, Roll S, Baumgart DC, Büning C, Wittig B, Wiedenmann B, Dignass A, Sturm A (2010) Impact of pain on health-related quality of life in patients with inflammatory bowel disease. World J Gastroenterol 16(25):3168-3177

8. Lesage AC, Hagège H, Tucat G, Gendre JP (2011) Results of a national survey on quality of life in inflammatory bowel diseases. Clin Res Hepatol Gastroenterol. 35(2):117-124

9. Iglesias M, Vázquez I, Barreiro-de Acosta M, Figueiras A, Nieto L, Piñeiro M, Gómez R, Lorenzo A, Domínguez Muñoz JE (2010) Health related quality of life in patients with Cohn's disease in remission. Rev Esp Enferm Dig 102(11):624-630

10. Drossman DA, Patrick DL, Mitchell CM, Zagami EA, Appelbaum MI (1989) Health-related quality of life in inflammatory bowel disease. Functional status and patient worries and concerns. Dig Dis Sci. 34(9):1379-1386

11. Casellas F, de Acosta BM, Iglesias M, Robles V, Nos P, Aguas M, Riestra S, de Francisco R, Papo M, Borruel N (2012) Mucosal healing restores normal health and quality of life in patients with inflammatory bowel disease. Eur J Gastroenterol Hepatol. 24(7):762-769

12. Calvet X, Gallardo O, Coronas R, Casellas F, Montserrat A, Torrejón A, Vergara M, Campo R, Brullet E (2006) Remission on thiopurinic immunomodulators normalizes quality of life and psychological status in patients with Crohn's disease. Inflamm Bowel Dis 12(8):692-696
13. Williet N, Sandborn WJ, Peyrin-Biroulet L (2014) Patient-reported outcomes as primary end points in clinical trials of inflammatory bowel disease. Clin Gastroenterol Hepatol 12(8):1246-1256

14. Schipper H (1990) Guidelines and caveats for quality of life measurement in clinical practice and research. Oncology (Williston Park). 4(5):51-57

15. Cross RK, Lapshin O, Finkelstein J (2008) Patient subjective assessment of drug side effects in inflammatory bowel disease. $\mathbf{J}$ Clin Gastroenterol 42(3):244-251

16. Thirlby RC, Land JC, Fenster LF, Lonborg R (1998) Effect of surgery on health-related quality of life in patients with inflammatory bowel disease: a prospective study. Arch Surg 133(8):826-832

17. Delaney CP, Kiran RP, Senagore AJ, O'Brien-Ermlich B, Church J, Hull TL, Remzi FH, Fazio VW (2003) Quality of life improves within 30 days of surgery for Crohn's disease. J Am Coll Surg 196(5):714-721

18. Tillinger W, Mittermaier C, Lochs H, Moser G (1999) Healthrelated quality of life in patients with Crohn's disease: influence of surgical operation - a prospective trial. Dig Dis Sci 44(5):932-938

19. Thaler K, Dinnewitzer A, Oberwalder M, Weiss EG, Nogueras JJ, Wexner SD (2005) Assessment of long-term quality of life after laparoscopic and open surgery for Crohn's disease. Colorectal Dis 7(4):375-381

20. Caprilli R, Gassull MA, Escher JC, Moser G, Munkholm P, Forbes A, Hommes DW, Lochs H, Angelucci E, Cocco A, Vucelic B, Hildebrand H, Kolacek S, Riis L, Lukas M, de Franchis R, Hamilton M, Jantschek G, Michetti P, O’Morain C, Anwar MM, Freitas JL, Mouzas IA, Baert F, Mitchell R, Hawkey CJ (2006) European evidence based consensus on the diagnosis and management of Crohn's disease: special situations. Gut 55(Suppl 1):i36-i58

21. Iaculli E, Agostini M, Biancone L, Fiorani C, Di Vizia A, Montagnese F, Sibio S, Manzelli A, Tesauro M, Rufini A, Sica GS (2016) C-reactive protein levels in the perioperative period as a predictive marker of endoscopic recurrence after ileo-colonic resection for Crohn's disease. Cell Death Discov 2:16032. https ://doi.org/10.1038/CDDiscovery.2016.32

22. Onali S, Calabrese E, Petruzziello C, Lolli E, Ascolani M, Ruffa A, Sica G, Rossi A, Chiaramonte C, Pallone F, Biancone L (2016) Post-operative recurrence of Crohn's disease: a prospective study at 5 years. Dig Liver Dis. 48(5):489-494

23. Onali S, Calabrese E, Petruzziello C, Zorzi F, Sica GS, Lolli E, Ascolani M, Condino G, Pallone F, Biancone L (2010) Endoscopic vs ultrasonographic findings related to Crohn's disease recurrence: a prospective longitudinal study at 3 years. J Crohns Colitis. 4(3):319-328

24. Biancone L, Onali S, Calabrese E, Petruzziello C, Zorzi F, Condino G, Sica GS, Pallone F (2008) Non-invasive techniques for assessing postoperative recurrence in Crohn's disease. Dig Liver Dis 40(2):265-270

25. Biancone L, Sica GS, Calabrese E, Onali S, Petruzziello C, Pallone F (2008) Frequency and pattern of endoscopic recurrence in Crohn's disease patients with ileo-colonic resection using a laparoscopic vs laparotomic approach: a prospective longitudinal study. Am J Gastroenterol 103(3):809-811

26. Thirlby RC, Sobrino MA, Randall JB (2001) The long-term benefit of surgery on health-related quality of life in patients with inflammatory bowel disease. Arch Surg 136(5):521-527

27. Scarpa M, Ruffolo C, D'Incà R, Filosa T, Bertin E, Ferraro S, Polese L, Martin A, Sturniolo GC, Frego M, D'Amico DF, Angriman I (2007) Health-related quality of life after ileocolonic resection for Crohn's disease: long-term results. Inflamm Bowel Dis 13(4):462-469

28. Haapamäki J, Turunen U, Roine RP, Färkkilä MA, Arkkila PE (2009) Impact of demographic factors, medication and symptoms on disease-specific quality of life in inflammatory bowel disease. Qual Life Res 18(8):961-969 
29. Moskovitz DN, Maunder RG, Cohen Z, McLeod RS, MacRae $\mathrm{H}$ (2000) Coping behavior and social support contribute independently to quality of life after surgery for inflammatory bowel disease. Dis Colon Rectum 43(4):517-521

30. Bullen TL, Sharpe L, Lawsin C, Patel DC, Clarke S, Bokey L (2012) Body image as a predictor of psychopathology in surgical patients with colorectal disease. J Psychosom Res 73(6):459-463

31. Siassi M, Weiss M, Hohenberger W, Lösel F, Matzel K (2009) Personality rather than clinical variables determines quality of life after major colorectal surgery. Dis Colon Rectum 52(4):662-668

32. Sica GS, Di Carlo S, Biancone L, Gentileschi P, Pallone F, Gaspari AL (2010) Single access laparoscopic ileocecal resection in complicated Crohn's disease. Surg Innov. 17(4):359-360

33. Duepree HJ, Senagore AJ, Delaney CP, Brady KM, Fazio VW (2002) Advantages of laparoscopic resection for ileocecal Crohn's disease. Dis Colon Rectum 45(5):605-610

34. Sica GS, Biancone L (2013) Surgery for inflammatory bowel disease in the era of laparoscopy. World J Gastroenterol 19(16):2445-2448

35. Patel SV, Patel SV, Ramagopalan SV, Ott MC (2013) Laparoscopic surgery for Crohn's disease: a meta-analysis of perioperative complications and long term outcomes compared with open surgery. BMC Surg. 24(13):14

36. Tabet J, Hong D, Kim CW, Wong J, Goodacre R, Anvari M (2001) Laparoscopic versus open bowel resection for Crohn's disease. Can J Gastroenterol. 15(4):237-242

37. Sica GS, Iaculli E, Benavoli D, Biancone L, Calabrese E, Onali S, Gaspari AL (2008) Laparoscopic versus open ileo-colonic resection in Crohn's disease: short- and long-term results from a prospective longitudinal study. J Gastrointest Surg. 12(6):1094-1102

38. Gomollón F, Dignass A, Annese V, Tilg H, Van Assche G, Lindsay JO, Peyrin-Biroulet L, Cullen GJ, Daperno M, Kucharzik T, Rieder F, Almer S, Armuzzi A, Harbord M, Langhorst J, Sans M, Chowers Y, Fiorino G, Juillerat P, Mantzaris GJ, Rizzello F, Vavricka S, Gionchetti P, ECCO (2017) 3rd European evidencebased consensus on the diagnosis and management of Crohn's disease 2016: part 1: diagnosis and medical management. J Crohns Colitis. 11(1):3-25

39. Gionchetti P, Dignass A, Danese S, Magro Dias FJ, Rogler G, Lakatos PL, Adamina M, Ardizzone S, Buskens CJ, Sebastian S, Laureti S, Sampietro GM, Vucelic B, van der Woude CJ, Barreiro-de Acosta M, Maaser C, Portela F, Vavricka SR, Gomollón F, ECCO (2017) 3rd European evidence-based consensus on the diagnosis and management of Crohn's disease 2016: part 2: surgical management and special situations. J Crohns Colitis. 11(2):135-149

40. Rieder F, Latella G, Magro F, Yuksel ES, Higgins PD, Di Sabatino A, de Bruyn JR, Rimola J, Brito J, Bettenworth D, van Assche G, Bemelman W, d'Hoore A, Pellino G, Dignass AU (2016) European Crohn's and colitis organisation topical review on prediction, diagnosis and management of fibrostenosing Crohn's disease. J Crohns Colitis. 10(8):873-885

41. Bemelman WA, Warusavitarne J, Sampietro GM, Serclova Z, Zmora O, Luglio G, de Buck van Overstraeten A, Burke JP, Buskens CJ, Colombo F, Dias JA, Eliakim R, Elosua T, Gecim IE, Kolacek S, Kierkus J, Kolho KL, Lefevre JH, Millan M, Panis Y, Pinkney T, Russell RK, Shwaartz C, Vaizey V, Yassin N, D'Hoore A (2018) ECCO-ESCP consensus on surgery for Crohn's disease. J Crohns Colitis. 12(1):1-16

42. Solina G, Mandalà S, La Barbera C, Mandalà V (2016) Current management of intestinal bowel disease: the role of surgery. Updates Surg. 68(1):13-23

43. Pellino G, Keller DS, Sampietro GM, Annese V, Carvello M, Celentano V, Coco C, Colombo F, Cracco N, Di Candido F, Franceschi M, Laureti S, Mattioli G, Pio L, Sciaudone G, Sica G, Villanacci V, Zinicola R, Leone S, Danese S, Spinelli A, Delaini G, Selvaggi F, the Italian Society of Colorectal Surgery (SICCR) (2020) Inflammatory bowel disease (IBD) position statement of the Italian Society of Colorectal Surgery (SICCR): general principles of IBD management. Tech Coloproctol 24(2):105-126

44. Ondrula DP, Nelson RL, Pradas ML, Coyle BW, Ab-carian H (1992) Multifactorial index of preoperative risk factors in colon resections. Dis Colon Rectum 35:117-122

45. Testini M, Margari A, Amoruso M, Lissidini G, Bonomo GM (2000) The dehiscence of colorectal anastomoses: the risk factors. Ann Ital Chir 71:433-440

46. Furst MB, Stromberg BV, Blatchford GJ, Christensen MA, Thorson AG (1994) Colonic anastomoses: bursting strength after corticosteroid treatment. Dis Colon Rectum 37(1):12-15

47. Gerdin L, Eriksson AS, Olaison G, Sjödahl R, Ström M, Söderholm JD, Myrelid P (2016) The Swedish Crohn Trial: a prematurely terminated randomized controlled trial of thiopurines or open surgery for primary treatment of ileocaecal Crohn's disease. J Crohns Colitis. 10(1):50-54

48. Ponsioen CY, de Groof EJ, Eshuis EJ, Gardenbroek TJ, Bossuyt PMM, Hart A, Warusavitarne J, Buskens CJ, van Bodegraven AA, Brink MA, Consten ECJ, van Wagensveld BA, Rijk MCM, Crolla RMPH, Noomen CG, Houdijk APJ, Mallant RC, Boom M, Marsman WA, Stockmann HB, Mol B, de Groof AJ, Stokkers PC, D'Haens GR, Bemelman WA, LIR!C study group (2017) Laparoscopic ileocaecal resection versus infliximab for terminal ileitis in Crohn's disease: a randomised controlled, open-label, multicentre trial. Lancet Gastroenterol Hepatol. 2(11):785-792

Publisher's Note Springer Nature remains neutral with regard to jurisdictional claims in published maps and institutional affiliations. 